\title{
An exploratory study of the need for curriculum review of Master of Public Health Degree at a Rural-based University in South Africa
}

Author:
Takalani G. Tshitangano ${ }^{1}$
Affiliation:
'Department of Public
Health, University of Venda,
South Africa
Corresponding author:
Takalani G. Tshitangano,
takalani.tshitangano@
univen.ac.za
Dates:
Received: 31 July 2015
Accepted: 29 Feb. 2016
Published: 20 May 2016
How to cite this article:
Tshitangano TG. An
exploratory study of the need
for curriculum review of
Master of Public Health
Deabile device
to read online.
Degree at a Rural-based
University in South Africa. Afr
J Prm Health Care Fam Med.
2016;8(2), a993. http://dx.
doi.org/10.4102/phcfm.
v8i2.993
Copyright:
C) 2016. The Authors.
Licensee: AOSIS. This work
is licensed under the
Creative Commons
Attribution License.

Background: Master of Public Health (MPH) training programmes were developed worldwide in response to the crisis in human resources for health.

Aim: To determine whether the MPH programme at the selected rural-based university in South Africa enabled students to achieve the MPH core competencies relevant for Lower Middle Income Countries.

Setting: The study was carried out at a rural-based University in South Africa. The target population was the 2011 first-year cohort of MPH students who by the beginning of 2014 had just completed their coursework.

Methodology: A quantitative cross-sectional descriptive research design was adapted. Eighty-five students were randomly selected to participate in the study. A structured questionnaire comprising seven competency clusters was developed. The selected students completed a self-administered questionnaire. Only those students who signed consent forms participated in this study. The questionnaire was tested for construct validity and reliability using 10 students with similar characteristics to those sampled for the study. Microsoft Excel software was used to analyse the data descriptively in terms of frequency and percentages.

Results: The students were confident of their competencies regarding public health science skills. Amongst these were analytical assessment, communication, community and intersectorial competencies as well as ethics. However, the students lacked confidence in contextsensitive issues, planning and management, research and development, and leadership competencies. Yet the latter is the backbone of public health practice.

Conclusion and recommendation: There is a need for revamping public health curricula. In this respect, a follow-up study that builds a deeper understanding of the subject is needed.

\section{Introduction}

Calhoun and Spencer et al. assert: 'Numerous political, economic, social and technological factors currently influence globalization, which is also driving the current unprecedented interest and growth in world health and global workforce development prioritizing capacity building both within and across nations ${ }^{\prime}{ }^{1}$ According to Calhoun and Spencer et al.:

in response to the crisis in human resources required to meet the world-wide demand for effective and efficient public health services, various Master of Public Health (MPH) training programs have been developed world wide. However, the long standing professional and geographic differences in MPH education and training programs, and roles and specialization requirements have compromised national health agenda globally.

\section{Calhoun, Ramaih et al. further state that:}

equally impacted has been consensus building regarding the development of MPH educational standards across universities. In response to the repeated calls for collaborations and inter-university education, a consensus has been reached regarding the core competencies of MPH students, and was validated across regions in recent decades. ${ }^{2}$

MPH competencies are defined as 'as a unique set of applied knowledge, skills and other attributes grounded in theory and evidence for the broad practice of public health'. ${ }^{2}$ The Association of Schools of Public Health (ASPH) identified core competencies for the Master of Public Health $(\mathrm{MPH})$ degree in graduate schools and programmes of public health. ${ }^{3}$ The ASPH represents the 
40 accredited schools of public health in North America, with a combined faculty of more than 7500 and an annual enrolment of nearly 1000 students. According to the ASPH:

to equip graduates for analysis and consideration of solutions to public health problems at the community, institutional, and societal levels, the MPH curriculum in graduate schools and programs of public health has traditionally been organized around five core disciplines namely, biostatistics, epidemiology, environmental health science, health policy and management, and social and behavioral sciences. ${ }^{3}$

However, the ASPH identified seven cross-cutting disciplines, namely, communication and informatics, diversity and culture, professionalism, programme planning, public health biology and systems thinking. Both core discipline competencies as well as cross-cutting competencies were validated in high-income countries. ${ }^{3}$

According to Moser: 'the following MPH core competencies were formulated and validated for low and middle-income countries (LMICs) in a study in which the University of Western Cape (South Africa) participated'. ${ }^{4}$

Despite the availability of the validated core competencies for LMICs, the selected rural-based university in South Africa continues to follow its MPH original programme comprising only discipline-specific competencies. The concern is that Moser who had more than 20 years of experience in hiring and supervising $\mathrm{MPH}$ graduates discovered a considerable variation in the depth and quality of MPH graduates' skills and knowledge in competency areas relevant to public health practice that fall outside their major field. ${ }^{5}$ Thus, Moser argues that both discipline-specific as well as the interdisciplinary and/or cross-cutting core competencies are intended to produce MPH graduates who can reliably be expected to possess a fundamental set of skills, regardless of their major field because successful public health practice requires knowledge and skills outside any $\mathrm{MPH}$ graduates' major field. ${ }^{5}$

However, it is not clear if the MPH programme at a selected university in South Africa covers the fundamental knowledge, attitudes and skills that every MPH student regardless of their major field should possess upon graduation. This study aimed at determining whether the MPH programme at the rural-based university in South Africa enables students to achieve the MPH core competencies relevant for LMICs.

\section{Purpose of the study}

This study was undertaken to determine whether the MPH programme at a selected rural-based university in South Africa enabled students to achieve the MPH core competencies relevant for LMICs.

\section{Research methods and design}

A quantitative cross-sectional descriptive design was adopted. Students who registered for the MPH degree for the first time from 2011 to 2013 and had just completed their coursework at the beginning of 2014 constituted the study population. Eighty-five students were randomly selected.

\section{Data collection and analysis}

A structured data collection instrument comprising 7 competency clusters, namely Public health science skills (including analytical assessment competencies; Communication competencies; Context-sensitive issues; Community and intersectorial competencies; Planning and management competencies; and Leadership and systems thinking competencies) where participants were expected to rate themselves competent or incompetent, was developed. Various authors were consulted to ensure construct validity of the instrument. $6,7,8,9,10,11,12$ The instrument was pretested using nine honours students from the school of health sciences of the same institution to test the clarity of the instrument and to determine the duration of completing the questionnaire. Informed written consent was obtained from all the respondents, including those used in the pretest of the instrument.

The data collection instrument was e-mailed to each individual student from an anonymous e-mail address to minimise study biasness. Thus, data were collected using self-administered questionnaires. The response rate was $92 \%$ $(n=78)$. Data were analysed using Excel spreadsheet to determine the frequencies. Data were presented using bar charts and tables.

\section{Results}

The results of this study are organised on the basis of the validated core competencies for LMICs.

Public health science skills including analytical assessment competencies

The majority of students $(92 \%, n=72)$ rated themselves competent on this core-competence as compared to only 6 students who rated themselves incompetent. In order to adequately assess this core-competence, the researcher added in the instrument an item named research and development, where about 91\% $(n=71)$ students rated themselves incompetent on the core-competence. Figures 1 and 2 present the details.

\section{Communication competencies}

Similarly, $92 \%$ of students rated themselves competent on this core-competence as compared to only 6 students who rated themselves incompetent (Tables 1 and 2).

\section{Context-sensitive issues}

About $89 \%(n=70)$ of students rated themselves incompetent on this co-competence as compared to few $(n=8)$ who rated themselves competent (Figure 3). 


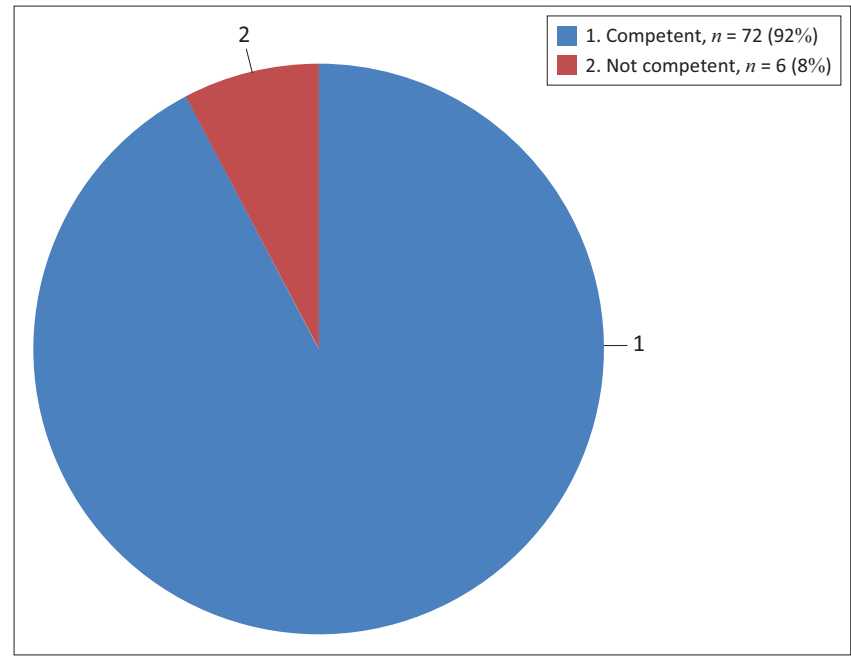

Source: Author's own work

FIGURE 1: Students' self-rating regarding public health science skills including analytical assessment competencies.

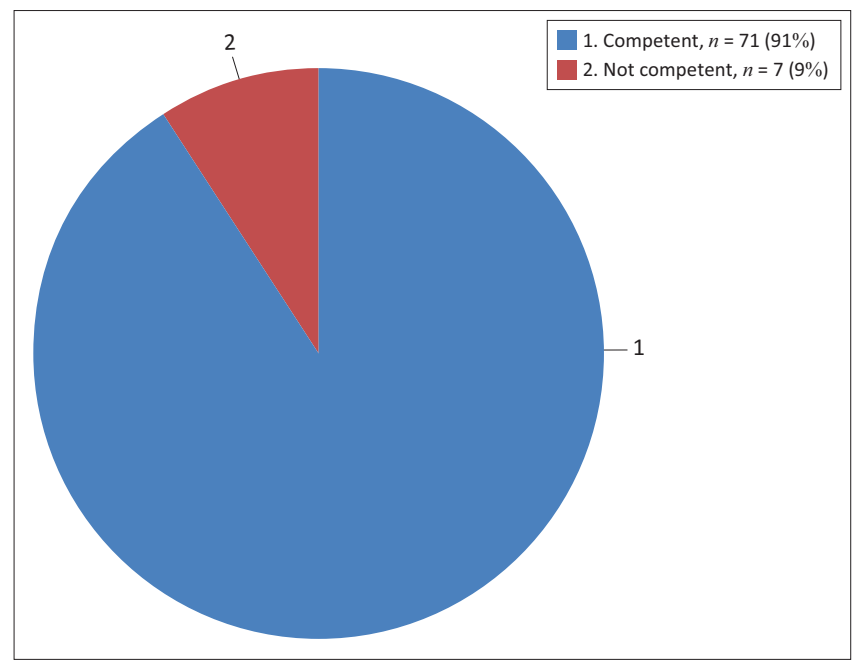

Source: Author's own work

FIGURE 2: Students' self-rating regarding their research and development competencies.

\section{Community and inter-sectorial competencies}

The majority (98\%) of students rated themselves competent in this core-competence, as compared to only $2 \%$ who rated themselves incompetent (Table 3).

\section{Planning and management competencies}

About $97 \%(n=76)$ of students rated themselves incompetent in this core-competence, as compared to $3 \%$ who rated themselves competent (Figure 4).

\section{Leadership and systems thinking competencies}

About $89 \%(n=70)$ of students rated themselves incompetent on this co-competence, as compared to few $(n=8)$ who rated themselves competent. The researcher further added an item on the instrument to measure students' competence on management of self, people and resources ethically, where the majority $(n=74)$ of students rated themselves competent. Figure 5 presents the details.

\section{Discussion}

The results of this study show that students at a selected university in South Africa are confident of their competency regarding public health science skills, including analytical assessment competencies, communication competencies, community and inter-sectorial competencies, and ethics. However, the study has revealed that students still lack confidence on context-sensitive issues, planning and management competencies, research and development, and leadership competencies, which are the backbone of the public health practice. This means that the programme at the selected university is putting much effort on imparting skills and knowledge on the graduate's major field neglecting fundamental skills that a successful public health practitioner requires.

TABLE 1: Validated Master of Public Health core competencies for low- and middle-income countries.

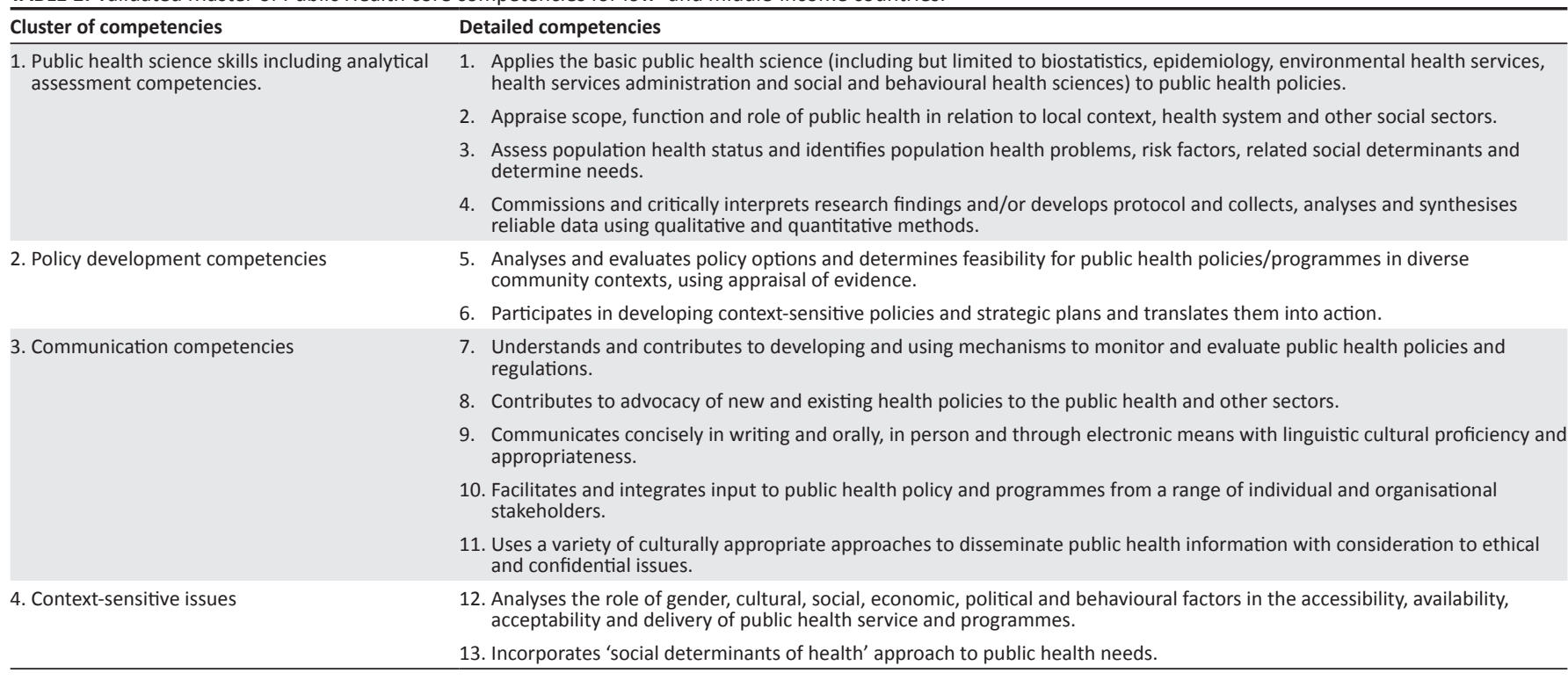




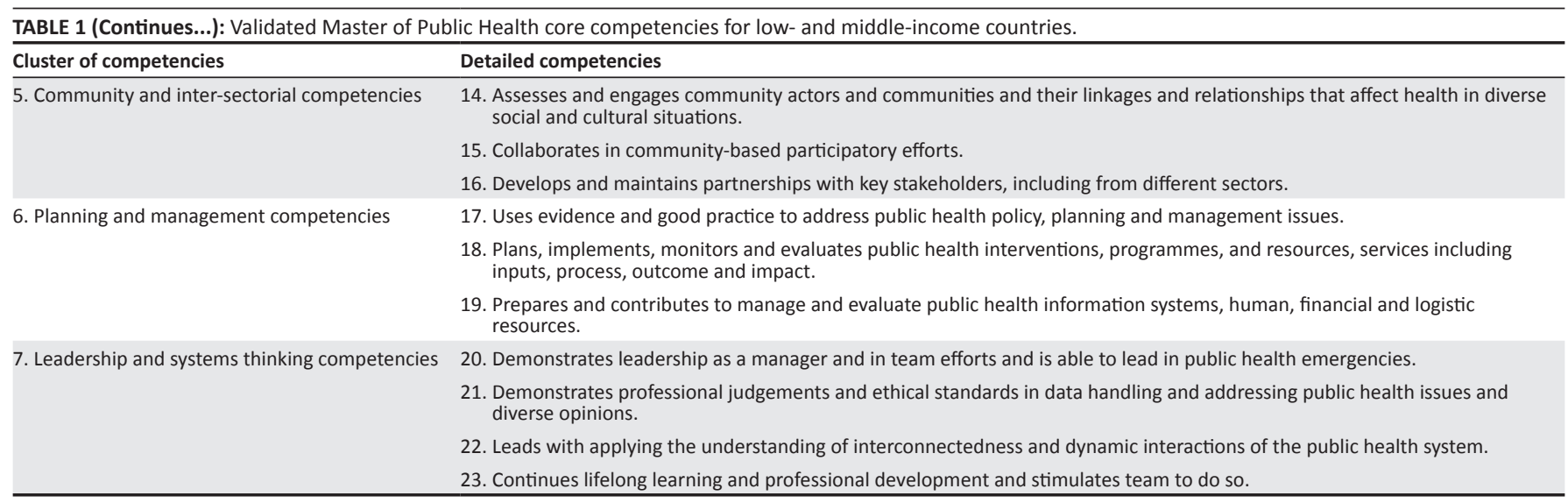

Source: The council on linkages between academia and public health practice ${ }^{5}$

TABLE 2: Frequency and percentages of communication competencies of Master of Public Health students.

\begin{tabular}{lcc}
\hline Communication & Frequency & Percentage \\
\hline Competent & 72 & 92 \\
Not competent & 6 & 8 \\
\hline
\end{tabular}

Source: Author's own work

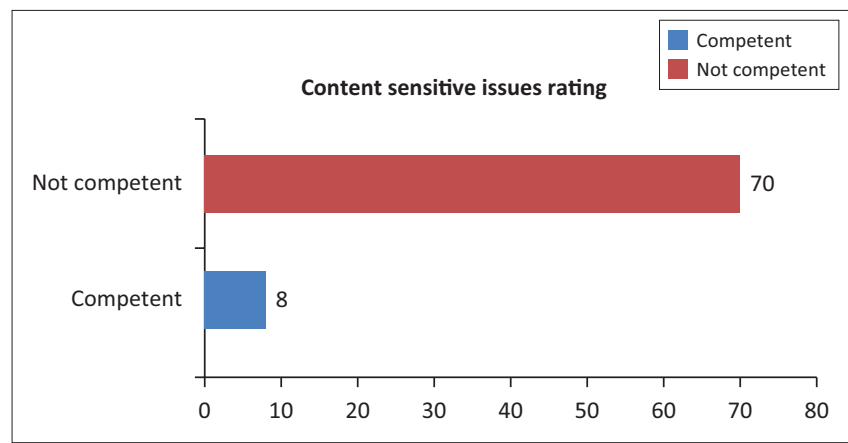

Source: Author's own work

FIGURE 3: Students' self-rating regarding their context-sensitive issues.

TABLE 3: Frequency and percentages of community and inter-sectorial competencies of Master of Public Health students.

\begin{tabular}{lcc}
\hline Communication & Frequency & Percentage \\
\hline Competent & 77 & 98 \\
Not competent & 1 & 2 \\
\hline
\end{tabular}

Source: Author's own work

The results of this study are similar to those of the situational assessment of the MPH programmes at the University of Toronto, which identified curriculum gaps in seven competencies, namely: ${ }^{13}$

- Develop strategies to motivate others for collaborative problem solving, decision making and evaluation.

- Use current technology to communicate effectively.

- Use skills such as team building, negotiation, conflict management and group facilitation to build partnership.

- Evaluate an action, policy or program.

- Demonstrate an ability to set and follow priorities, and to maximise outcomes based on available resources.

- Apply principles of program planning, development, budgeting, management and evaluation in organisational and/or community initiatives.

- Demonstrate knowledge of Canada's public health systems (e.g. federal, provincial and local).

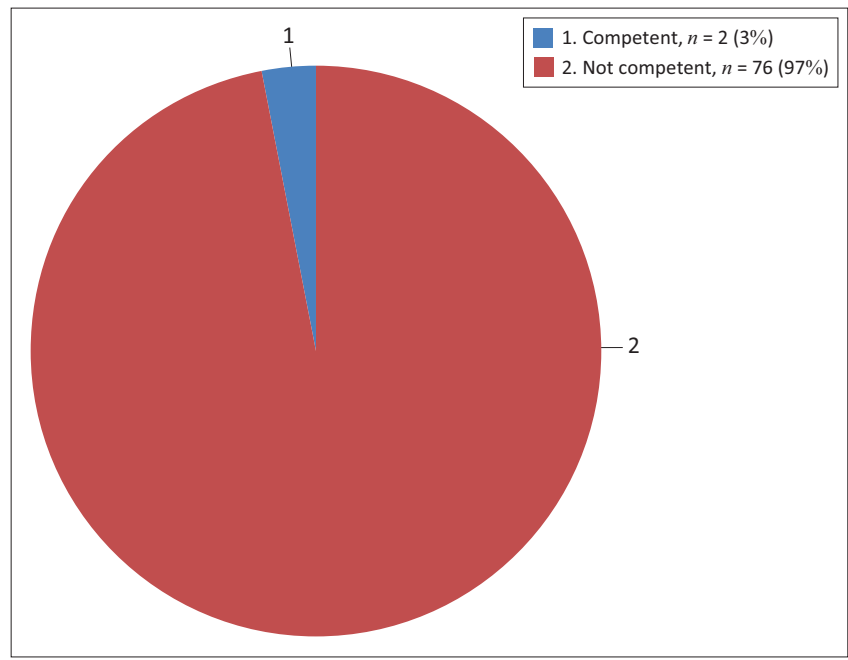

Source: Author's own work

FIGURE 4: Students' self-rating regarding their planning and management competencies.

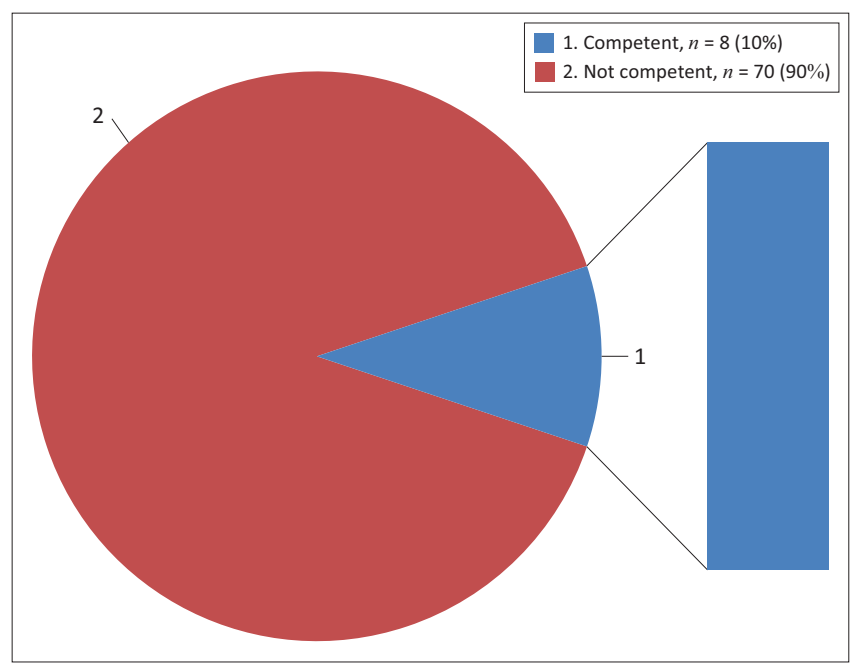

Source: Author's own work

FIGURE 5: Students' self-rating regarding their leadership and systems thinking competencies.

\section{Limitations of the study}

The study was conducted amongst MPH students registered at only one South African University. Thus, generalisability of the findings is limited to this institution only. 


\section{Conclusion and recommendations}

There are serious gaps in the MPH degree curriculum at the selected rural-based university in South Africa. The gaps in the competencies have implications for curriculum, in the form of curriculum review in order to ensure that the MPH curriculum of the selected university in South Africa and the overall educational experience prepares our graduates to adapt and excel in their discipline-specific fields as well as the cross-cutting fields in order to tackle the public health issues of today and the future effectively.

The selected university should adopt the vision and mission statements together with the goals and objectives of the MPH suggested by public health associations for LMICs worldwide. The 23 core competencies should be adopted alongside the seven core competency clusters. In-depth consultation with lecturers and students, including alumni, for specific feedback to inform the curriculum should be considered. Issues surrounding practical should also be considered. Discipline-specific competencies for all fields in the MPH programme as well as strategies to address gaps in the current curriculum should be identified.

\section{Acknowledgements}

The author thanks the students who consented to participate in this study.

\section{Competing interests}

The author declares that she has no financial or personal relationships which may have inappropriately influenced her in writing this article.

\section{References}

1. Calhoun JG, Spencer HC, Buekens P. Competencies for global health graduate education. Infect Dis Clin North Am. 2011;25:575-592. http://dx.doi.org/10.1016/ jidc.2011.02.015.0891-5520/11/\$

2. Calhoun JG, Ramiah K, Weist EM, Shortell SM. Development of a core competency model for the master of public health degree. Am J Public Health. 2008;98(9): 1598-1607. http://dx.doi.org/10.2105/ajph.2007.117978

3. The Association of Schools of Public Health core competencies-University of lowa College of Public Health [document on the internet]. 2006 [cited 2014 Sept 12] Available from: www.public-health.uiowa.edu/asph-core-competencies/

4. Moser JM. Core academic competencies for Master of public health students: One health department practitioner's perspective. Am J Public Health. 2008;98(9):1559-1561. http://dx.doi.org/10.2105/ajph.2007.117234

5. The Council on Linkages between Academia and Public health practice. Core competencies for public health professionals Tier 1, Tier 2 and Tier 3 [document on the internet]. 2010 [cited 2014 Aug 2]. Available from: http:www.phf.org/ on the internet]. 2010 [cited 2014 Aug 2]. Available from: http:www.phf.org/
resourcetools/documents/corecompetenciesforpublichealthprofessionals2010 may.pdf

6. Birt CA, Foldspang A. The developing role of systems of competencies in public health education and practice. Public Health Rev. 2011;14(1):134-147

7. Calhoun JG, Davidson PL, Sinioris ME, Vincent ET, Griffith JR. Towards an understanding of competency identification and assessment in health care. Qual Manag Health Care. 2002;11(1):14-38. http://dx.doi.org/10.1097/00019514200211010-00006

8. Wright J, Rao M, Walker K. The UK public health skills and career framework Could it help to make public health the business of every workforce? Public Health. 2008;122(6):541-544. http://dx.doi.org/10.1016/j.puhe.2008.03.006

9. Genat B, Robinson P, Parker E. Foundation competencies for Master of Public health graduates in Australia. Brisbane QUT publications: Australia network of Academic Public health institutions [document on the internet]. 2009 [cited 2014 Aug 4]. Available from: www.health.nsw.gov.au/training/aphti/.../aphti_ competencyframework.p

10. Public Health Foundations of India. Report of international conference on new directions for public health education in low and middle income countries. Processes, proceedings and proposed next steps. Hyderabad, India: Public Health Foundations; 2008

11. Magana VL. Essential skills regional framework public health, Latin America, working paper. Cuernavaca: INSP/MEX Dr. Charles Godue, OPS/OMS; 2011.

12. Zwanikken PA, Alexander L, Huong NT, et al. 2014. Validation of public health competencies and impact variables for low-and middle-income countries. BMC Public Health. 2014;14:55. http://dx.doi.org/10.1186/14712458-14-55

13. Foisy J. A situational assessment of $\mathrm{MPH}$ programs at the Dallas Lana School of Public Health, University of Toronto [document on the internet]. 2012 [cited 2014 Sept 2]. Available from: http://resources.cpha.ca/CPHA/Conf/Data/2014/a14 164e.pptx 